\title{
NÍVEIS DE CÁLCIO E RELAÇÃO CÁLCIO: FÓSFORO EM RAÇÕES PARA POEDEIRAS LEVES DE 24 A 40 SEMANAS DE IDADE
}

\section{LEVELS OF CALCIUM AND CALCIUM: PHOSPHORUS RATIO IN DIETS FOR LAIYNG HENS AGED 24 TO 40 WEEKS}

\author{
Cassia Rampini Vellasco ${ }^{1}$ \\ Paulo Cezar Gomes ${ }^{1}$ \\ Juarez Lopes Donzele ${ }^{1}$ \\ Horacio Santiago Rostagno ${ }^{1}$ \\ Arele Arlindo Calderano ${ }^{1}$ \\ Heloisa Helena de Carvalho Mello ${ }^{*}$ \\ Silvana Marques Pastore ${ }^{1}$ \\ ${ }^{1}$ Universidade Federal de Viçosa, Viçosa, MG, Brasil. \\ ${ }^{2}$ Escola de Veterinária e Zootecnia da Universidade Federal de Goiás, Goiânia, GO, Brasil \\ *Autora para correspondência - heloisamello@gmail.com
}

\begin{abstract}
Resumo
Objetivou-se determinar a exigência nutricional de cálcio e a melhor relação cálcio:fósforo em rações para poedeiras leves de 24 a 40 semanas de idade. Foram utilizadas 324 aves Hy-Line W-36, distribuídas em delineamento inteiramente casualizado, esquema fatorial $3 \times 3$, sendo três níveis de cálcio $(3,9 ; 4,2$ e 4,5 \%) e três relações cálcio/fósforo $(9,3 ; 10,53$ e 12,12/1), totalizando nove tratamentos, seis repetições e seis aves por unidade experimental. Avaliou-se o desempenho produtivo, a qualidade do ovo, as características ósseas, o balanço de cálcio e fósforo e a mortalidade. Não houve interação $(\mathrm{P}>0,05)$ entre os níveis de cálcio e as relações cálcio/fósforo para nenhuma das variáveis, porém os níveis de cálcio promoveram efeito $(\mathrm{P}<0,05)$ sobre o peso e porcentagem da casca, cálcio na casca, ovos perdidos, consumo de cálcio e fósforo, cálcio e fósforo na excreta, cálcio e fósforo retido. A relação cálcio/fósforo influenciou significativamente $(\mathrm{P}<0,05)$ o consumo de ração, ganho de peso, conversão alimentar, consumo de cálcio e fósforo, fósforo na excreta e fósforo retido. Rações contendo 4,5\% de cálcio e relação cálcio:fósforo de 12,12:1, correspondendo ao consumo de cálcio de 3,71 g/ave/dia e de fósforo de $306 \mathrm{mg} / \mathrm{ave} / \mathrm{dia}$, garantem desempenho satisfatório em rações para poedeiras leves no período de 24 a 40 semanas.
\end{abstract}

Palavras-chave: aves; minerais; ovos; produção.

\begin{abstract}
The objective of this study was to determine the nutritional requirement for calcium and the best calcium:phosphorus ratio in the diet for laying hens from 24 to 40 weeks of age. 324 Hy-Line W-36 birds were distributed in a completely randomized design in $3 \times 3$ factorial scheme, consisting of three levels of calcium $(3.9,4.2$, and $4.5 \%)$ and three calcium:phosphorus ratios $(9.3,10.53$, and 12.12:1) totaling nine treatments, six replicates and six birds each. We evaluated performance, egg quality, bone characteristics, balance of calcium and phosphorus, and mortality. There was no interaction $(\mathrm{P}>0.05)$ between calcium levels and calcium:phosphorus ratio for the variables, but levels of calcium affected $(\mathrm{P}<0.05)$ weight and shell percentage, calcium in the shell, lost eggs,
\end{abstract}


consumption of calcium and phosphorus, calcium and phosphorus excretion, and retained calcium and phosphorus. The calcium:phosphorus ratio affected significantly $(\mathrm{P}<0.05)$ feed intake, weight gain, feed conversion per dozen eggs, egg mass, calcium and phosphorus intake, phosphorus excretion, and retained phosphorus. Diets containing 4.5\% calcium and the calcium:phosphorus ratio of 12,12:1, corresponding to a calcium intake of $3.71 \mathrm{~g} / \mathrm{hen} /$ day and phosphorus of $306 \mathrm{mg} /$ bird /day, guarantee satisfactory performance in diets for laying hens from 24 to 40 weeks.

Keywords: egg; minerals; poultry; production.

Enviado em: 18 outubro 2013

Aceito em: 22 dezembro de 2015

\section{Introdução}

O cálcio tem sido utilizado em grande quantidade nas rações, devido à sua exigência ser expressa em cálcio total e ao baixo custo do calcário. A consequência desta prática é que o cálcio em excesso pode agir como antagonista na digestibilidade de outros minerais, formando quelatos insolúveis e dificultando a absorção de outros minerais, especialmente fósforo, sódio, potássio, magnésio, ferro, cobre, zinco e manganês, causando deficiência secundária ${ }^{(1)}$.

O cálcio e o fósforo são considerados minerais importantes na nutrição das poedeiras, pois, além de sua participação nas funções vitais, como componente principal das estruturas ósseas, no equilíbrio ácido-básico e nos sistemas enzimáticos, são componentes principais da casca do ovo. A casca do ovo tem peso médio de 5 a $6 \mathrm{~g}$, dos quais aproximadamente $2 \mathrm{~g}$ são de cálcio ${ }^{(2)}$.

Para a formação do ovo, a ave necessita consumir quantidade adequada de cálcio e de fósforo por dia a fim de atender a necessidade desses minerais, para formar a casca, depositar na gema, repor as perdas teciduais e manter a homeostasia iônica, a qual é regulada pela concentração plasmática da forma ionizada do cálcio e do fósforo. A função nutricional do cálcio está estreitamente relacionada à do fósforo, devido à forte interação entre eles.

O excesso de cálcio pode interferir na absorção de outros minerais, afetando homeostasia desses minerais ${ }^{(1)}$. Dietas deficientes em cálcio ocasionam diminuição da produção de ovos e ocorrência de casca fina ou porosa, já as dietas deficientes em fósforo levam a alterações no metabolismo energético de carboidratos, aminoácidos e gordura, nos processos químicos do sangue, no crescimento do esqueleto, no transporte de ácidos graxos e de outros lipídios. Níveis elevados de fósforo prejudicam a liberação do cálcio ósseo e a adequada mineralização da casca, resultando em má qualidade da casca do ovo. Portanto, ao se formular a ração, deve-se buscar a relação entre esses minerais que seja mais apropriada para as aves e que produza menor excreção destes minerais. $\mathrm{O}$ uso indevido dos níveis de cálcio e de fósforo e da relação entre eles acarreta prejuízo ao esqueleto das galinhas, ocasionando perdas na qualidade da casca dos ovos e redução da vida produtiva da poedeira $^{(3)}$.

Objetivou-se determinar a exigência nutricional de cálcio e a melhor relação cálcio/fósforo em dieta de poedeiras leves de 24 a 40 semanas de idade.

\section{Material e Métodos}

O experimento foi realizado no Setor de Avicultura, do Departamento de Zootecnia do Centro de Ciências Agrárias da Universidade Federal de Viçosa - MG, no período de janeiro a maio de 2009. Foram utilizadas 324 poedeiras da marca comercial Hy-Line W-36, no período de 24 a 40 semanas de idade. As aves foram adquiridas com 20 semanas de idade, distribuídas em gaiolas e, até entrarem em fase experimental (24 semanas), foram manejadas conforme o recomendado pelo manual da linhagem e alimentadas seguindo as recomendações de Rostagno et al. ${ }^{(4)}$.

Com 24 semanas de idade, as poedeiras foram distribuídas nas unidades experimentais, tendo sido padronizadas por peso corporal e por postura. As aves foram distribuídas em um delineamento 
inteiramente casualizado em arranjo fatorial $3 \times 3$, consistindo de três níveis de cálcio $(3,9 ; 4,2$ e $4,5 \%)$ e três relações cálcio/fósforo $(9,3,10,53$ e 12,12/1) totalizando nove tratamentos, com seis repetições e seis aves por unidade experimental.

As aves foram alojadas, duas por gaiola ( $25 \times 40$ x $45 \mathrm{~cm})$, num galpão convencional de postura com dimensões $24 \times 8 \mathrm{~m}$, fechado nas laterais com tela e coberto com telhas de barro.

As dietas foram suplementadas com cálcio e fósforo, utilizando-se fosfato bicálcico de textura média e calcário (50\% fino e 50\% grosso). Foram realizadas análises para determinação dos teores de fósforo e cálcio do fosfato bicálcico, calcário, milho e farelo de soja, além da granulometria do calcário e do fosfato bicálcico (Tabela 1).

Tabela 1: Análise de cálcio, de fósforo e da granulometria (DGM) dos ingredientes

\begin{tabular}{lccc}
\hline Ingrediente & DGM $(\mathbf{m m})$ & Cálcio \% & Fósforo \% \\
\hline Fosfato bicálcico & 1,8 & 23,26 & 19,21 \\
Calcário fino & 0,3 & 38,19 & - \\
Calcário grosso & 3,8 & 39,19 & - \\
Milho & - & 0,03 & 0,08 \\
Farelo de Soja & - & 0,24 & 0,53 \\
\hline
\end{tabular}

As dietas experimentais (Tabela 2) foram isonutritivas, exceto para cálcio e fósforo. As exigências nutricionais das poedeiras, quanto aos demais nutrientes, foram atendidas conforme Rostagno et al. ${ }^{(4)}$.

As dietas foram fornecidas diariamente em dois horários, às 8:00 e às 16:00 horas, e o fornecimento de água foi à vontade, durante todo o experimento. O período experimental teve duração de dezesseis semanas, subdividido em quatro períodos de coleta de ovos de 28 dias cada.

As temperaturas médias, mínima e máxima, no interior do galpão foram monitoradas diariamente por três termômetros de máxima e de mínima, que estavam distribuídos pelo galpão posicionados à altura das aves. O sistema de iluminação adotado foi o de 17 horas de luz diária, controlado por meio de um relógio analógico (timer), que permitiu o acender e o apagar das luzes durante o período da noite e da madrugada, conforme o procedimento adotado nas granjas comerciais.

As seguintes variáveis foram avaliadas: produção de ovos, massa de ovos, peso médio dos ovos, ganho de peso das aves, consumo de ração, conversão alimentar por dúzia de ovo (kg/dz), conversão alimentar por quilograma de ovo $(\mathrm{kg} / \mathrm{kg})$, consumo de cálcio, consumo de fósforo, peso e percentagem da casca, gema e clara, espessura da casca, gravidade específica dos ovos, ovos perdidos (ovos trincados, de casca fina e sem casca), mortalidade, teores de matéria mineral na casca de ovo, teores de cálcio e fósforo na casca de ovo.

Ao final do experimento (40 semanas), seis aves por tratamento foram abatidas por deslocamento cervical para retirada das tíbias e posterior análise da matéria mineral na tíbia. A tíbia direita foi utilizada para determinação do teor de fósforo e de cálcio, sendo identificada por tratamento e por repetição. As análises seguiram a metodologia descrita por Silva \& Queiroz ${ }^{(5)}$. A matéria mineral foi determinada em porcentagem da matéria mineral seca da tíbia.

Para a determinação do balanço de cálcio e fósforo, durante os cinco dias finais do período experimental, utilizaram-se 162 poedeiras distribuídas em delineamento inteiramente casualizado em arranjo fatorial 3x3, consistindo de três níveis de cálcio $(3,9 ; 4,2$ e 4,5 \%) e três relações cálcio/ fósforo $(9,3 ; 10,53$ e 12,12), totalizando nove tratamentos, com três repetições e seis aves por unidade experimental. A ração e a água foram fornecidas às aves à vontade. Ao final desse período, as sobras dos comedouros e dos baldes foram pesadas e o consumo de ração foi calculado pela diferença entre a ração fornecida e as sobras de ração.

O consumo de cálcio e de fósforo foi obtido pelo consumo de ração total desse período e multiplicado 
pelo nível de cálcio e de fósforo do tratamento a ser determinado e dividido por 100. Durante esse período, as excretas das aves foram coletadas duas vezes ao dia, utilizando-se bandejas revestidas com plástico. As excretas recolhidas em cada unidade experimental, após a retirada de penas, resíduos de ração e outras fontes de contaminação, foram transferidas para sacos plásticos devidamente identificados e armazenados em freezer. Posteriormente, o conteúdo armazenado foi descongelado, homogeneizado, pesado por repetição e uma alíquota de $200 \mathrm{~g}$ foi retirada e mantida em estufa de ventilação forçada por 72 horas a $55^{\circ} \mathrm{C}$ para secagem. Em seguida, as excretas foram expostas ao ar, para entrar em equilíbrio com a temperatura e umidade do ambiente. Posteriormente, foram pesadas, moídas em moinho de bola e acondicionadas para as análises laboratoriais.

Para determinação da matéria seca, as excretas foram secas em estufa a $105^{\circ} \mathrm{C}$ por 16 horas e, para determinação da matéria mineral, foram queimadas a $550{ }^{\circ} \mathrm{C}$ por 4 horas. A solução mineral foi preparada conforme metodologia descrita por Silva \& Queiroz $^{(5)}$, utilizando-se os procedimentos da via úmida. Da solução mineral, foram determinados os teores de fósforo, pelo método colorimétrico, e de cálcio pelo método de absorção atômica. Os teores de matéria mineral, de cálcio e de fósforo foram expressos em gramas e em porcentagem da matéria seca da excreta. Após a obtenção dos resultados das analises laboratoriais, calculou-se o balanço de cálcio e de fósforo.

Os resultados obtidos com as aves recebendo diferentes níveis de cálcio e relações cálcio/fósforo foram analisados por meio de análises de variância e regressão, conforme ajustamento dos dados, mediante o programa Statistical Analisys System (SAS) versão 9.2, utilizando nível de 5\% de probabilidade.

Tabela 2: Composição percentual das dietas experimentais

\begin{tabular}{lccccccccc}
\hline & \multicolumn{10}{c}{ Tratamentos } \\
\hline Ingrediente \% & $\mathbf{1}$ & $\mathbf{2}$ & $\mathbf{3}$ & $\mathbf{4}$ & $\mathbf{5}$ & $\mathbf{6}$ & $\mathbf{7}$ & $\mathbf{8}$ & $\mathbf{9}$ \\
\hline Ração basal $^{1}$ & 86,65 & 86,65 & 86,65 & 86,65 & 86,65 & 86,65 & 86,65 & 86,65 & 86,65 \\
Calcário & 9,16 & 9,01 & 8,85 & 9,89 & 9,73 & 9,56 & 10,63 & 10,45 & 10,27 \\
Fosfato bicálcico & 1,19 & 1,45 & 1,70 & 1,33 & 1,61 & 1,88 & 1,47 & 1,76 & 2,06 \\
Areia lavada & 3,00 & 2,90 & 2,80 & 2,13 & 2,02 & 1,91 & 1,26 & 1,14 & 1,03 \\
Total & 100 & 100 & 100 & 100 & 100 & 100 & 100 & 100 & 100 \\
\hline Composição nutricional (\%) & 3,90 & 3,90 & 3,90 & 4,20 & 4,20 & 4,20 & 4,50 & 4,50 & 4,50 \\
\hline Cálcio & 0,322 & 0,370 & 0,419 & 0,347 & 0,399 & 0,452 & 0,371 & 0,427 & 0,484 \\
Fósforo & 12,12 & 10,53 & 9,3 & 12,12 & 10,53 & 9,3 & 12,12 & 10,53 & 9,3 \\
Relação & & & & & & & & & \\
Cálcio/Fósforo & & & & & & & & & \\
\hline
\end{tabular}

\footnotetext{
${ }^{1}$ Ração basal: Milho 52,77\%; Soja farelo (45\%) 24,09\%; Óleo de soja 4,65\%; Glútem de milho (60\%) 4,00\%; Sal comum 0,56\%; DL-Metionina ( $99 \%$ ) 0,23\%; L-Lisina HCl (78,4\%) 0,10\%; L-Triptofano ( $99 \%$ ) $0,02 \%$; Carbonato de potássio $0,03 \%$; Cloreto de colina 0,04\%; Mistura Vitamínica 0,10\%; Mistura Mineral 0,05\%; Antioxidante 0,01\%; Variável 13,35\%.

${ }^{2}$ Dietas experimentais: Proteína Bruta 17,53\%; Energia Metabolizável $2.900 \mathrm{kcal} / \mathrm{kg}$; Lisina digestível $0,84 \%$; Metionina+Cistina digestível $0,76 \%$; Metionina digestível $0,51 \%$; Treonina digestível $0,60 \%$; Triptofano digestivel 0,19\%; Valina digestível 0,70\%; Arginina digestível 1,04\%; Fenilalanina digestível $0,86 \%$; Fenilalanina+Tirosina digestivel 1,48\%; Glicina + Serina 1,59\%; Histidina digestivel 0,44\%; Isoleucina digestível 0,70\%; Sódio 0,24\%; Cloro $0,37 \%$; Potássio $0,61 \%$; Ácido Linoléico 3,68\%.

Mistura vitamínica - Composição/kg: vit. A 12.000 .000 U.I.; vit D3 3.600.000 U.I.; vit. E 3.500 U.I.; vit B1 500 mg; vit B2 $8.000 \mathrm{mg}$; vit B6 $3.000 \mathrm{mg}$; ácido pantotênico $12.000 \mathrm{mg}$; biotina $200 \mathrm{mg}$; vit. K $3.000 \mathrm{mg}$; ácido fólico 3.500 $\mathrm{mg}$; ácido nicotínico $40.000 \mathrm{mg}$; vit. B12 $20.000 \mathrm{mg}$; selênio $130 \mathrm{mg}$; veículo q.s.p. $1.000 \mathrm{~g}$.

Mistura mineral - Composição/kg: manganês $160 \mathrm{~g}$; ferro $100 \mathrm{~g}$; zinco $100 \mathrm{~g}$, cobre $20 \mathrm{~g}$; cobalto 2 g; iodo 2 g; excipiente q.s.p. 1.000 g. 3Butil-hidroxi-tolueno (BHT).
} 


\section{Resultados e Discussão}

A temperatura máxima e mínima média durante todo o período experimental foi de 19,7 e $29,9{ }^{\circ} \mathrm{C}$, respectivamente, indicando que a temperatura estava fora da faixa de termoneutralidade, que, segundo o Guia de Manejo Hy Line W-36(6) está entre 18 e $27^{\circ} \mathrm{C}$ para poedeiras.

Não houve interação $(\mathrm{P}<0,05)$ entre os fatores estudados (níveis de cálcio e relações cálcio/fósforo) para nenhuma das variáveis avaliadas.

Não houve efeito $(\mathrm{P}>0,05)$ dos níveis de cálcio sobre a taxa de postura, peso dos ovos, massa dos ovos, ganho de peso, consumo de ração e conversão alimentar (Tabela 3). Quanto à relação cálcio/ fósforo, houve efeito linear $(\mathrm{P}<0,05)$ sobre o ganho de peso, o consumo de ração e a conversão alimentar por dúzia de ovo e por massa de ovo. Os níveis de cálcio e as relações cálcio/fósforo não afetaram $(\mathrm{P}>0,05)$ o peso dos ovos, estando de acordo com Keshavarz \& Nakajima ${ }^{(7)}$, Oliveira et al. ${ }^{(8)}$.

Tabela 3: Desempenho produtivo das poedeiras leves de 24 a 40 semanas de idade

\begin{tabular}{|c|c|c|c|c|c|c|c|c|c|}
\hline \multirow[t]{2}{*}{ Variáveis } & \multicolumn{3}{|c|}{ Níveis de cálcio (\%) } & \multirow[t]{2}{*}{ Efeito } & \multicolumn{3}{|c|}{ Relação Cálcio/Fósforo } & \multirow[t]{2}{*}{ Efeito } & \multirow[t]{2}{*}{$\mathrm{CV}^{1}(\%)$} \\
\hline & 3,9 & 4,2 & 4,5 & & $12,12: 1$ & $10,53: 1$ & $9,30: 1$ & & \\
\hline Postura (\%) & 85,45 & 87,46 & 86,50 & $\mathrm{~ns}$ & 86,64 & 85,75 & 87,02 & ns & 3,25 \\
\hline Peso Ovo $(\mathrm{g})$ & 55,88 & 55,07 & 55,28 & $\mathrm{~ns}$ & 55,58 & 55,46 & 55,20 & ns & 2,73 \\
\hline Massa Ovos (g/ave/dia) & 47,70 & 48,10 & 47,75 & $\mathrm{~ns}$ & 48,10 & 47,50 & 48,00 & $\mathrm{~ns}$ & 4,52 \\
\hline Ganho de Peso (g/ave $)^{2}$ & $-0,67$ & 14,21 & 20,65 & $\mathrm{~ns}$ & $-3,81$ & 16,40 & 21,62 & $\mathrm{~L}^{*}$ & 38,54 \\
\hline $\begin{array}{l}\text { Consumo Ração } \\
(\mathrm{g} / \text { ave } / \text { dia })^{3}\end{array}$ & 82,60 & 82,55 & 82,50 & $\mathrm{~ns}$ & 81,63 & 82,31 & 83,69 & $\mathrm{~L}^{*}$ & 2,77 \\
\hline $\begin{array}{l}\text { Conversão alimentar } \\
\text { dúzia }(\mathrm{Kg} / \mathrm{dz})^{4}\end{array}$ & 1,13 & 1,10 & 1,12 & $\mathrm{~ns}$ & 1,09 & 1,12 & 1,13 & $\mathrm{~L}^{*}$ & 2,48 \\
\hline $\begin{array}{l}\text { Conversão alimentar } \\
\text { Massa ovos }(\mathrm{kg} / \mathrm{kg})^{5}\end{array}$ & 1,76 & 1,73 & 1,75 & $\mathrm{~ns}$ & 1,70 & 1,74 & 1,81 & $\mathrm{~L}^{*}$ & 3,54 \\
\hline $\begin{array}{l}\mathrm{L}^{*} \text { : Efeito linear significati } \\
{ }^{1} \text { Coeficiente de variação } \\
{ }^{2} \mathrm{Ganho} \text { de peso, } \mathrm{Y}=109,33 \\
{ }^{3} \text { Consumo de ração, } \mathrm{Y}=90 \text {, } \\
{ }^{4} \text { Conversão alimentar } / \text { dúzi } \\
{ }^{5} \text { Conversão alimentar } / \text { mass }\end{array}$ & $\begin{array}{l}0,05) \mathrm{p} \\
\mathrm{IX} \\
0, \mathrm{Y}=1, \\
0, \mathrm{Y}=2\end{array}$ & $\begin{array}{l}011 \mathrm{X} \\
042 \mathrm{X}\end{array}$ & não s & (1) & vo $(\mathrm{P}>0,05$ & pelo test & & & \\
\hline
\end{tabular}

Não foi verificado efeito $(\mathrm{P}>0,05)$ dos tratamentos utilizados sobre a massa de ovos. $\mathrm{O}$ ganho de peso e o consumo de ração não foram afetados $(\mathrm{P}>0,05)$ pelos níveis de cálcio na dieta. Resultados diferentes foram obtidos por Keshavarz et al. ${ }^{(7)}$, que verificaram diminuição do consumo de ração de poedeiras com 22 semanas de idade, quando aumentou o nível de cálcio de 3,5 para 4,2\%. Quanto à relação cálcio/fósforo na dieta, o consumo de ração e o ganho de peso aumentaram de forma linear $(\mathrm{P}<0,05)$ com a diminuição dos valores das relações cálcio/fósforo, ou seja, com o aumento dos níveis de fósforo houve aumento no consumo de ração e no ganho de peso. Keshavarz ${ }^{(9)}$ verificaram redução no consumo de ração quando poedeiras receberam dieta com baixos teores de fósforo disponível $(0,2$ e $0,1 \%)$.

A conversão alimentar por dúzia e conversão alimentar por massa de ovo melhoraram de forma linear $(\mathrm{P}<0,05)$ com o aumento dos valores das relações cálcio/fósforo. Em outras palavras, quanto 
maior o valor da relação cálcio/fósforo, menor era o nível de fósforo da dieta; portanto, com o aumento dos níveis de fósforo houve aumento no consumo de ração e piora na conversão alimentar por dúzia e por massa de ovo.

Não houve efeito $(\mathrm{P}>0,05)$ dos níveis de cálcio e fósforo sobre a mortalidade das aves. A mortalidade durante o período estudado foi de $0,93 \%$, sendo duas aves no tratamento com 3,9\% de cálcio e relação $\mathrm{Ca} / \mathrm{P}$ de 12,12:1 e uma ave no tratamento com 4,2\% de cálcio e relação $\mathrm{Ca} / \mathrm{P}$ de 12,12:1. A taxa de mortalidade ficou abaixo do número citado como normal pelo manual da linhagem Hyline ${ }^{(6)}$, que é de $1,60 \%$ até as 40 semanas de idade.

A relação cálcio: fósforo não afetou a qualidade dos ovos (Tabela 4). Entretanto, os níveis de cálcio afetaram $(\mathrm{P}<0,05)$ a qualidade da casca, o teor de cálcio na casca e a percentagem de ovos perdidos (Tabela 4).

Tabela 4: Qualidade de ovo das poedeiras leves de 24 a 40 semanas de idade

\begin{tabular}{|c|c|c|c|c|c|c|c|c|c|}
\hline \multirow{2}{*}{ Variáveis } & \multicolumn{3}{|c|}{$\begin{array}{c}\text { Níveis de cálcio } \\
(\%)\end{array}$} & \multirow{2}{*}{ Efeito } & \multicolumn{3}{|c|}{ Relação Cálcio/Fósforo } & \multirow{2}{*}{ Efeito } & \multirow{2}{*}{$C V^{1}(\%)$} \\
\hline & 3,9 & 4,2 & 4,5 & & $12,12: 1$ & $10,53: 1$ & $9,30: 1$ & & \\
\hline Peso Ovo (g) & 55,88 & 55,07 & 55,28 & ns & 55,58 & 55,46 & 55,20 & ns & 2,73 \\
\hline Gema $(\%)$ & 24,30 & 24,44 & 24,21 & ns & 24,20 & 24,34 & 24,40 & $\mathrm{~ns}$ & 2,23 \\
\hline Albúmen (\%) & 66,65 & 66,25 & 66,37 & ns & 66,52 & 66,35 & 66,40 & ns & 0,93 \\
\hline Casca $(g)^{2}$ & 5,03 & 5,16 & 5,23 & $L^{*}$ & 5,15 & 5,16 & 5,11 & $\mathrm{~ns}$ & 3,83 \\
\hline Casca $(\%)^{3}$ & 9,05 & 9,30 & 9,41 & $L^{*}$ & 9,27 & 9,30 & 9,19 & ns & 3,55 \\
\hline Espessura Casca (mm) & 0,24 & 0,23 & 0,23 & $\mathrm{~ns}$ & 0,24 & 0,23 & 0,23 & ns & 8,66 \\
\hline Gravidade Especifica $\left(\mathrm{g} / \mathrm{cm}^{3}\right)$ & 1,10 & 1,08 & 1,09 & ns & 1,08 & 1,09 & 1,10 & $\mathrm{~ns}$ & 8,26 \\
\hline Matéria mineral Casca (\%) & 91,94 & 91,87 & 91,78 & ns & 91,81 & 91,58 & 92,20 & ns & 1,28 \\
\hline Matéria mineral Casca (g) & 4,58 & 4,69 & 4,74 & ns & 4,68 & 4,67 & 4,64 & ns & 4,05 \\
\hline Cálcio na Casca $(\%)^{4}$ & 31,58 & 31,64 & 32,18 & $L^{*}$ & 31,83 & 31,78 & 31,80 & $\mathrm{~ns}$ & 2,76 \\
\hline Cálcio na Casca $(\mathrm{g})^{5}$ & 1,57 & 1,62 & 1,67 & $L^{*}$ & 1,64 & 1,62 & 1,61 & $\mathrm{~ns}$ & 6,18 \\
\hline Fósforo na Casca (\%) & 0,085 & 0,085 & 0,082 & $\mathrm{~ns}$ & 0,085 & 0,083 & 0,084 & $\mathrm{~ns}$ & 6,93 \\
\hline Fósforo na Casca (mg) & 4,3 & 4,8 & 4,2 & ns & 4,9 & 4,2 & 4,3 & $\mathrm{~ns}$ & 27,90 \\
\hline Ovos Perdidos $(\%)^{6}$ & 1,04 & 0,69 & 0,46 & $L^{*}$ & 0,68 & 0,95 & 0,56 & ns & 94,52 \\
\hline
\end{tabular}

$L^{*}$ Efeito linear significativo $(P<0,05)$ pelo teste $F$; ns: não significativo $(P>0,05)$ pelo teste $F$;

${ }^{2}$ Coeficiente de variação; ${ }^{2} \mathrm{Casca}, \mathrm{Y}=3,76+0,33 \mathrm{NCa} ;{ }^{3} \mathrm{Casca}, \mathrm{Y}=6,76+0,60 \mathrm{NCa} ;{ }^{4} \mathrm{Cálcio} \mathrm{na} \mathrm{casca,}$ $\mathrm{Y}=27,58-1,00 \mathrm{NCa} ;{ }^{5} \mathrm{C}$ álcio na casca, $\mathrm{Y}=0,96+0,15 \mathrm{NCa} ;{ }^{6} \mathrm{Ovos}$ perdidos; $\mathrm{Y}=4,76-0,96 \mathrm{NCa}$.

Os resultados obtidos para percentagem de gema e de albúmen não foram afetados $(\mathrm{P}>0,05)$ pelos níveis de cálcio na dieta, estando de acordo com Pelícia et al. ${ }^{(10)}$, que trabalharam com poedeiras leves de segundo ciclo de produção (90 semanas) e com níveis de 3,0 e 4,5\% de cálcio na dieta e também não observaram efeito dos níveis de cálcio para estas variáveis. O aumento da disponibilidade de cálcio se reflete primeiramente na qualidade externa do ovo, ou seja, na qualidade de casca sendo menos sensível sua atuação na qualidade interna do ovo.

$\mathrm{O}$ peso e o percentual de casca foram afetados linearmente $(\mathrm{P}<0,05)$ pelos níveis de cálcio na dieta. Resultados semelhantes foram obtidos por Chowdhury \& Smith ${ }^{(11)}$, que trabalharam com níveis de cálcio de 2,5 a 4,0\% e com poedeiras leves de 30 semanas de idade e verificaram que com o 
aumento dos níveis de cálcio houve aumento linear no peso e no percentual da casca. Contudo, as relações cálcio/fósforo não influenciaram $(\mathrm{P}>0,05)$ estas variáveis. $\mathrm{O}$ aumento no percentual de casca do ovo com o aumento do nível de cálcio na dieta pode ser resultado do aumento no teor de cálcio da casca, estando de acordo com o resultado encontrado por Pelicia et al. ${ }^{(10)}$, que observaram elevação de cálcio na casca conforme elevou-se o cálcio na dieta.

Os resultados obtidos para espessura da casca e para gravidade específica não foram afetados $(\mathrm{P}>0,05)$ pelos níveis de cálcio e pela relação cálcio/fósforo das dietas. Por outro lado, Rodrigues et al. ${ }^{(12)}$ avaliaram níveis de cálcio de 0,$5 ; 2,0$ e 3,5\% e poedeiras leves com 68 semanas de idade e verificaram que o nível de $2,0 \%$ de cálcio na dieta promoveu aumento na espessura da casca dos ovos. Não houve diferença $(\mathrm{P}>0,05)$ das relações cálcio/fósforo sobre as variáveis de espessura de casca e gravidade específica. Resultados semelhantes foram obtidos por Faria et al. ${ }^{(13)}$, que trabalharam com poedeiras leves de 60 semanas de idade, não verificaram efeito dos níveis de fósforo $(0,35 ; 0,45$ e $0,55 \%)$ sobre estas mesmas variáveis.

Os valores de matéria mineral na casca ( $\mathrm{g}$ e \%) não foram afetados $(\mathrm{P}>0,05)$ tanto pelos níveis de cálcio quanto pelas relações cálcio/fósforo na dieta. Resultados semelhantes foram obtidos por Nunes et al. (2), que trabalharam com poedeiras semipesadas de 16 semanas de idade e diferentes níveis de cálcio $(0,6 ; 1,2 ; 1,8$ e $2,4 \%)$ e observaram que a quantidade de matéria mineral nas cascas não foi influenciada pelos teores de cálcio nas rações.

$\mathrm{O}$ aumento dos níveis de cálcio na dieta promoveu aumento linear $(\mathrm{P}<0,05)$ do cálcio na casca do ovo ( $\mathrm{g}$ e \%). Os níveis de cálcio afetaram linearmente $(\mathrm{P}<0,05)$ a percentagem de ovos perdidos, ou seja, com o aumento dos níveis de cálcio na dieta houve diminuição da percentagem de ovos perdidos. Resultados semelhantes foram obtidos por Oliveira et al. ${ }^{(14)}$, que verificaram redução nas perdas dos ovos com o aumento dos níveis de cálcio na dieta de poedeiras semipesadas com 42 semanas de idade.

Estudar os fatores que afetam a qualidade da casca de ovos é prioritário, visto as significativas perdas financeiras provenientes de deformidades e das quebras. Roland ${ }^{(15)}$ relatou perdas de até $13 \%$ dos ovos, em virtude da baixa qualidade da casca, mas que podem totalizar até $20 \%$, quando considerado o percurso até o consumidor final.

Os níveis de cálcio e as relações cálcio/fósforo não tiveram efeito $(\mathrm{P}>0,05)$ sobre as características ósseas de poedeiras leves no período de 24 a 40 semanas de idade (Tabela 5).

Não houve diferença $(\mathrm{P}>0,05)$ no peso da tíbia entre os níveis de cálcio e as relações cálcio/fósforo estudadas. Resultado semelhante foi encontrado por Safaa et al. ${ }^{(16)}$, que avaliaram fontes e níveis de cálcio (3,5 e 4,0\%) para poedeiras semipesadas no período de 58 a 73 semanas de idade e não constataram diferença $(\mathrm{P}>0,05)$ no peso da tíbia atribuída aos níveis de cálcio na ração.

Não houve influência $(\mathrm{P}>0,05)$ dos níveis de cálcio nem das relações cálcio/fósforo sobre a matéria mineral ou sobre a deposição de cálcio na tíbia, tanto em percentagem como em gramas. Resultados semelhantes foram obtidos por Vargas Jr. et al. ${ }^{(17)}$ em estudo com cinco níveis de cálcio $(0,60 ; 0,70$; 0,$80 ; 0,90$ e 1,00\%) para poedeiras leves de 7 a 12 semanas de idade. Os autores observaram ausência de diferenças entre a matéria mineral óssea e cálcio ósseo. Do mesmo modo, Araújo et al. ${ }^{(18)}$, ao avaliarem níveis de fósforo disponível $(0,28 ; 0,38$ e $0,48 \%)$ em rações contendo $3,5 \%$ de cálcio para poedeiras semipesadas no período de 24 a 58 semanas de idade, não encontraram influência das relações cálcio/fósforo sobre a porcentagem de matéria mineral nas tíbias das poedeiras. Keshavarz et al. ${ }^{(9)}$ demonstraram que com níveis mais baixos de fósforo a matéria mineral da tíbia é significativamente menor.

Apesar de não ter sido verificado efeito $(\mathrm{P}>0,05)$ dos níveis de cálcio da ração sobre a deposição de fósforo e de cálcio na tíbia, vários estudos comprovam que baixos níveis de cálcio na ração de poedeiras promovem mobilização óssea de cálcio para suprir a necessidade da ave e manter a qualidade de $\operatorname{casca}^{(19-20)}$. 
Tabela 5: Características de osso das poedeiras leves de 24 a 40 semanas de idade

\begin{tabular}{|c|c|c|c|c|c|c|c|c|c|}
\hline \multirow{2}{*}{ Variáveis } & \multicolumn{3}{|c|}{$\begin{array}{c}\text { Níveis de cálcio } \\
(\%)\end{array}$} & \multirow{2}{*}{ Efeito. } & \multicolumn{3}{|c|}{$\begin{array}{c}\text { Relação } \\
\text { Cálcio/Fósforo }\end{array}$} & \multicolumn{2}{|c|}{ Efeito $C V^{1}(\%)$} \\
\hline & 3,9 & 4,2 & 4,5 & & 12,12:1 & 10,53: & $9,30: 1$ & & \\
\hline Peso da Tíbia (g) & 5,79 & 5,70 & 5,58 & ns & 5,73 & 5,71 & 5,63 & ns & 11,73 \\
\hline Matéria mineral Tíbia (\%) & 45,47 & 45,64 & 45,17 & ns & 45,32 & 44,92 & 46,04 & ns & 6,65 \\
\hline Matéria mineral Tíbia (g) & 2,64 & 2,62 & 2,53 & ns & 2,61 & 2,58 & 2,60 & $\mathrm{~ns}$ & 16,94 \\
\hline Cálcio na Tíbia (\%) & 13,02 & 13,80 & 13,00 & ns & 12,96 & 12,81 & 12,95 & ns & 7,73 \\
\hline Cálcio na Tíbia (mg) & 13,00 & 12,80 & 12,90 & ns & 12,90 & 12,80 & 12,90 & ns & 7,76 \\
\hline Fósforo na Tíbia (\%) & 6,24 & 6,20 & 6,27 & $\mathrm{~ns}$ & 6,23 & 6,18 & 6,30 & $\mathrm{~ns}$ & 8,33 \\
\hline Fósforo na Tíbia (g) & 0,45 & 0,43 & 0,44 & ns & 0,45 & 0,44 & 0,43 & $\mathrm{~ns}$ & 12,18 \\
\hline
\end{tabular}

$L^{*}$ Efeito linear significativo $(P<0,05)$ pelo teste $F$; ns: não significativo $(P>0,05)$ pelo teste $F$;

1 Coeficiente de variação

As relações cálcio/fósforo não afetaram $(\mathrm{P}>0,05)$ os teores de cálcio e de fósforo na tíbia. Araújo et al. ${ }^{(18)}$ estudaram os níveis de fósforo disponível $(0,28 ; 0,38$ e $0,48 \%)$, em rações contendo $3,5 \%$ de cálcio, para poedeiras semipesadas no período de 24 a 58 semanas de idade e também não encontraram influência das relações cálcio/fósforo sobre a porcentagem de cálcio e de fósforo na tíbia das aves.

Não foram observados efeitos $(\mathrm{P}>0,05)$ do nível de cálcio e da relação $\mathrm{Ca} / \mathrm{P}$ sobre a matéria mineral da excreta (Tabela 6). Resultados semelhantes foram obtidos por Pelícia et al. ${ }^{(10)}$, que trabalharam com poedeiras leves de segundo ciclo de produção (90 semanas) e níveis de 3,0 a 4,5\% de cálcio e 0,25 a $0,40 \%$ de fósforo na dieta, também verificaram que os níveis de cálcio e de fósforo não influenciaram na matéria mineral da excreta. Por outro lado, o consumo de cálcio aumentou linearmente $(\mathrm{P}<0,05)$ tanto pela elevação dos níveis de cálcio quanto pelo aumento dos níveis de fósforo na dieta em virtude da diminuição da relação $\mathrm{Ca} / \mathrm{P}$. Houve aumento linear $(\mathrm{P}<0,05)$ nos valores de cálcio excretado ( $\mathrm{g}$ e \%) com o aumento dos níveis de cálcio na dieta, porém o percentual de cálcio retido diminuiu linearmente $(\mathrm{P}<0,05)$. O mesmo não ocorreu $(\mathrm{P}>0,05)$ com os diferentes valores da relação cálcio/fósforo, sobre estas variáveis.

O consumo de cálcio e de fósforo aumentou linearmente $(\mathrm{P}<0,05)$ de acordo com os níveis de cálcio e com a diminuição das relações $\mathrm{Ca} / \mathrm{P}$, podendo ser explicado pelo maior consumo de ração e, consequentemente, maior consumo de cálcio e de fósforo, reduzindo, desta forma, o aproveitamento desses minerais pelo organismo, sendo eliminado nas excretas.

Verificou-se efeito linear $(\mathrm{P}<0,05)$ dos níveis de cálcio da dieta sobre o cálcio retido $(\mathrm{g}$ e \%). Os níveis de cálcio afetaram o consumo desse mineral com efeito linear e positivo sobre o cálcio retido e sobre a quantidade de cálcio nas excretas. De acordo com as equações lineares para retenção e excreção de cálcio, verificou-se que sua excreção aumentou $1,85 \mathrm{~g} /$ dia, enquanto a retenção aumentou 1,47 g/dia, por ponto percentual de cálcio na dieta. Consequentemente, houve um efeito decrescente na eficiência de retenção de cálcio à medida que se aumentou o nível de cálcio na dieta. Estando de acordo com os resultados encontrados neste trabalho, Chowdhury \& Smith ${ }^{(11)}$ observaram efeito crescente do aumento dos níveis de cálcio da dieta sobre as perdas de cálcio nas excretas e redução na retenção do cálcio.

$\mathrm{O}$ fósforo excretado em gramas e em percentagem aumentou linearmente $(\mathrm{P}<0,05)$ de acordo com a inclusão de cálcio nas rações. Houve aumento linar $(\mathrm{P}<0,05)$ da percentagem de fósforo com a 
redução da relação $\mathrm{Ca} / \mathrm{P}$.

Houve maior retenção de fósforo $(\mathrm{P}<0,05)$ tanto com o aumento dos níveis de cálcio quanto com

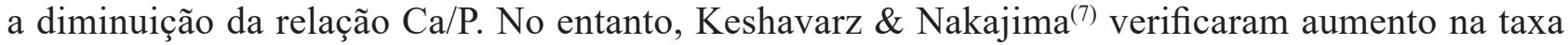
de passagem da digesta de poedeiras semipesadas de 30 semanas de idade, alimentadas com níveis de $0,40,0,35$ e $0,30 \%$ de fósforo, causando redução em sua absorção e por consequencia maior eliminação nas excretas.

Tabela 6: Concentração de minerais na excreta e balanço do cálcio e fósforo das poedeiras leves de 24 a 40 semanas de idade

\begin{tabular}{|c|c|c|c|c|c|c|c|c|c|}
\hline \multirow{3}{*}{ Variáveis } & \multirow{2}{*}{\multicolumn{3}{|c|}{$\begin{array}{c}\text { Níveis de cálcio } \\
(\%)\end{array}$}} & \multirow{3}{*}{ Efeito. } & \multicolumn{3}{|c|}{ Relação } & \multirow{3}{*}{ Efeito } & \multirow{3}{*}{$\begin{array}{l}\mathrm{CV}^{1} \\
(\%)\end{array}$} \\
\hline & & & & & Cál & cio/Fósf & oro & & \\
\hline & 3,9 & 4,2 & 4,5 & & \multicolumn{3}{|c|}{ 12,12:1 10,53:1 9,30:1 } & & \\
\hline Mineral na Excreta (\%) & 32,93 & 34,07 & 38,74 & ns & 35,02 & 33,24 & 37,50 & ns & 17,52 \\
\hline Mineral na Excreta (g) & 29,04 & 28,97 & 33,76 & ns & 30,51 & 29,12 & 32,15 & ns & 20,05 \\
\hline Consumo de Cálcio (g/ave/dia) ${ }^{2}$ & 3,21 & 3,47 & 3,73 & $L^{*}$ & 3,43 & 3,46 & 3,52 & $L^{*}$ & 2,75 \\
\hline Cálcio na Excreta $(\%)^{3}$ & 3,09 & 3,34 & 4,40 & $\mathrm{~L}^{*}$ & 3,75 & 3,60 & 3,50 & $\mathrm{~ns}$ & 8,31 \\
\hline Cálcio na Excreta (g) ${ }^{4}$ & 2,72 & 2,84 & 3,83 & $\mathrm{~L}^{*}$ & 3,27 & 3,15 & 2,97 & ns & 10,23 \\
\hline Cálcio Retido $(\%)^{5}$ & 77,49 & 78,12 & 72,52 & $\mathrm{~L}^{*}$ & 74,92 & 76,00 & 77,20 & ns & 3,14 \\
\hline Cálcio retido $(\mathrm{g})^{6}$ & 10,25 & 11,12 & 11,14 & $\mathrm{~L}^{*}$ & 10,68 & 10,82 & 11,01 & ns & 6,17 \\
\hline Consumo Fósforo (g/ave/dia) ${ }^{7}$ & 0,30 & 0,33 & 0,35 & $L^{*}$ & 0,28 & 0,33 & 0,38 & $\mathrm{~L}^{*}$ & 2,80 \\
\hline Fósforo Excretado (\%) ${ }^{8}$ & 0,15 & 0,17 & 0,19 & $\mathrm{~L}^{*}$ & 0,15 & 0,17 & 0,18 & $L^{*}$ & 8,76 \\
\hline Fósforo Excretado $(\mathrm{g})^{9}$ & 0,13 & 0,14 & 0,16 & $\mathrm{~L}^{*}$ & 0,13 & 0,15 & 0,16 & ns & 14,13 \\
\hline Fósforo Retido (\%) & 88,52 & 88,04 & 87,44 & ns & 87,25 & 88,00 & 88,76 & ns & 1,75 \\
\hline Fósforo Retido $(\mathrm{g})^{10}$ & 1,1 & 1,19 & 1,27 & $\mathrm{~L}^{*}$ & 1,02 & 1,19 & 1,36 & $L^{*}$ & 5,32 \\
\hline \multicolumn{10}{|c|}{ 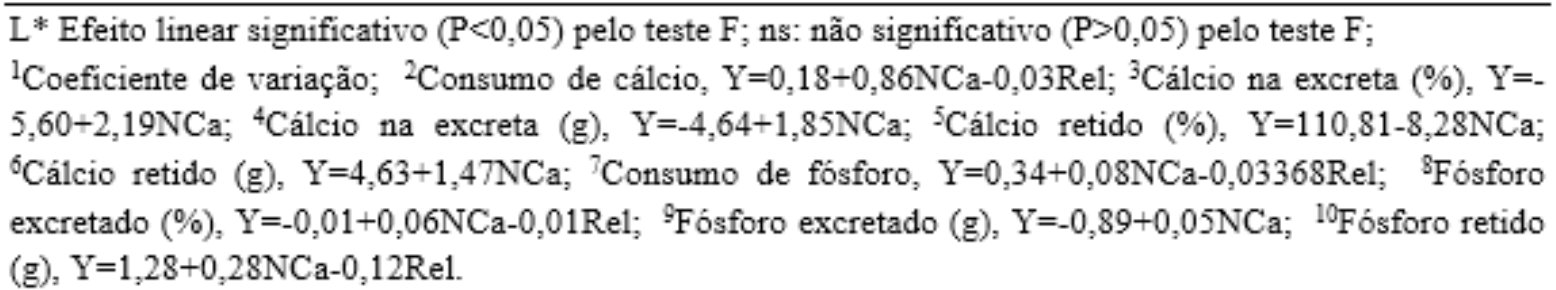 } \\
\hline
\end{tabular}

\section{Conclusão}

A exigência de cálcio para poedeiras leves, no período de 24 a 40 semanas de idade, é de 4,5\% e a relação cálcio/fósforo é de 12,12:1, correspondendo a 3,7g/ave/dia de cálcio e $306 \mathrm{mg} / \mathrm{ave} / \mathrm{dia}$ de fósforo.

\section{Referências}

1.Anderson KE; Harvenstein GB; Brake J. Effects of strain and rearing dietary regimens on brown-egg pullet growth and strain, rearing dietary regimens, density, and feed space effects on subsequent laying performance. Poultry Science. 1995; 74:1079-1092. 
2.Nunes RV; Pozza PC; Scherer C; Campestrini E; Rocha, LD; Nunes CGV; Costa FGP. Efeito dos teores de cálcio para poedeiras semipesadas durante a fase de pré-postura e no início da postura. Revista Brasileira de Zootecnia. 2006; 35(5):2007- 2012.

3.Jardim Filho RM; Stringhini JH; Café MB; Leandro NSM; Cunha WCP; Nascimento Júnior O. Influência das fontes e granulometria do calcário calcítico sobre o desempenho e qualidade da casca dos ovos de poedeiras comerciais. Acta Scientiarum. 2005; 27: 35-4.

4.Rostagno HS; Albino LFT; Donzele JL et al. Tabelas brasileiras de exigências nutricionais para aves e suínos (Composição de alimentos e exigências nutricionais). Viçosa, MG: Universidade Federal de Viçosa, 2005. $141 \mathrm{p}$.

5. Silva DJ \& Queiroz AC. Análises de alimentos - Métodos químicos e biológicos. 3ed. Viçosa: UFV, 2002. 235p.

6.Hy line s.d. Manual de manejo Hy-line. Granjas Ito, Sumaré, Brasil, 2009, 44p.

7.Keshavarz K; Nakajima S. Re-evaluation of calcium and phosphorus requirements of laying hens for optimum performance and eggshell quality. Poultry Science. 1993; 72(1):144-153.

8.Oliveira JEF; Oliveira BL; Bertechini AG. Níveis de cálcio granulometria e horário de fornecimento de calcário no desempenho e na qualidade do ovo de poedeiras leves no segundo ciclo de postura. Ciência e Agrotecnologia. 1997; 21:502-510.

9.Keshavarz K. The effect of different levels of nonphytate phosphorus with and without phytase on theperformance of four strains of laying hens. Poultry Science. 2003; 82:71- 91.

10.Pelícia K; Garcia EA; Faitarone ABG; Silva AP; Berto DA;Molino AB; Vercese F. Calcium and Available Phosphorus levels for laying hens in second production cycle. Brazilian Journal of Poultry Science. 2009; 11(1): 39-49.

11.Chowdhury SR; Smith TK. Dietary interaction of 1,4-diaminobutane (putrescine) and calcium on eggshell quality and performance in laying hens. Poultry Science. 2002; 81:84-9.

12.Rodrigues EA et al. Níveis de cálcio em rações de poedeiras comerciais no segundo ciclo de postura. Acta Scientiarum Animal Sciences. 2005; 27(1):49-54.

13.Faria DE; Junqueira OM; Sakomura NK; Santana AE. Efeito de diferentes níveis de sódio e fósforo sobre o desempenho e a qualidade da casca dos ovos de poedeiras comerciais. Revista Brasileira de Zootecnia. 2000; 29(2):458-466.

14.Oliveira JR; Bertechini AG; Fassani EJ et al. Níveis de cálcio em dietas para poedeiras leves e semipesadas no segundo ciclo de produção. Revista Ciência e Agrotecnologia. 2002; 26(5):1060-1067.

15.Roland DA. Egg shell quality III: calcium and phosphorus requirements of commercial leghorns. World Poultry Science Journal. 1986; 42(2):154-165.

16.Safaa HM; Serrano MP; Valencia DG et al. Productive Performance and egg quality of Brown egg-laying hens in the late phase of production as influenced by level and source of calcium in the diet. Poultry Science. 2008; 87:2043-2051.

17.Vargas JR; Albino LFT; Rostagno HS; Gomes PC; Carvalho DCO; Cupertino ES; Toledo RS e Pinto R. Níveis Nutricionais de Cálcio e de Fósforo Disponível para Aves de Reposição Leves e Semipesadas de 13 a 20 Semanas de Idade. Revista Brasileira de Zootecnia. 2004; 33(5):1263-1273.

18.Araújo LF; Junqueira OM; Araújo CSS, Savietto D, Albuquerque R; Barbosa LCGS. Níveis de fósforo disponível e tamanho de partículas do fosfato bicálcico na dieta de poedeiras comerciais de 24 a 58 semanas de idade. Revista Brasileira de Zootecnia. 2010; 39:1223-1227. 
19.Schreiweis MA; Orban JI; Ledur MC; Hester PY. The use densitometry to detect differences in bone mineral density and content of live white Leghorns fed varying levels o dietary calcium. Poultry Science. 2003; 82:1292-1301.

20.Almeida Paz ICL; Mendes AA; Balog A; Komiyama CM; Takahashi SE; Almeida ICL; García EA; Vulcano LC; Ballarin AW; Silva MC; Cardoso KFG. Efeito do cálcio na qualidade óssea e de ovos de poedeiras. Revista Archivos de Zootecnia. 2009; 58:173-183. 